BULLETIN Bulletin hispanique

HispaniquE Université Michel de Montaigne Bordeaux

113-1 | 2011

Actes de 2 colloques

\title{
La edición zaragozana a mediados del siglo XVII y la sistematización del libro de poesía
}

\author{
Pedro Ruiz Pérez
}

\section{OpenEdition}

Journals

Edición electrónica

URL: http://journals.openedition.org/bulletinhispanique/1316

DOI: 10.4000/bulletinhispanique.1316

ISSN: $1775-3821$

Editor

Presses universitaires de Bordeaux

Edición impresa

Fecha de publicación: 1 junio 2011

Paginación: 69-101

ISBN: 978-2-86781-740-3

ISSN: 0007-4640

Referencia electrónica

Pedro Ruiz Pérez, "La edición zaragozana a mediados del siglo XVII y la sistematización del libro de poesía », Bulletin hispanique [En línea], 113-1 | 2011, Publicado el 01 junio 2014, consultado el 19 abril 2019. URL : http://journals.openedition.org/bulletinhispanique/1316 ; DOI : 10.4000/

bulletinhispanique.1316 


\title{
La edición zaragozana a mediados del siglo Xvir y la sistematización del libro de poesía ${ }^{1}$
}

\author{
Pedro Ruiz Pérez \\ Universidad de Córdoba
}

Dans la Saragosse des années 1650 à 1660, l'activité significative des poètes et des presses donne une impulsion incontestable à la constitution d'un modèle de livre de poésie et fixe les voies de son développement. Des poètes de renom, liés à d'importants réseaux de relations dans un cadre commun et une tendance généralisée à la production imprimée, fournissent quelques clés pour comprendre le développement et la consolidation du processus.

En la conformación del modelo del libro de poesía la relevante actividad de prensas y poetas en Zaragoza entre 1650 y 1660 representa un impulso incuestionable y marca las lineas de su desarrollo. Poetas destacados, con una espesa trama de relaciones en un marco compartido y una generalizada inclinación a la imprenta, proporcionan algunas de las claves para el desarrollo y afianzamiento del proceso.

Poets and prints in Zaragoza between 1650 and 1660 play a very important role in the process of creation of the model of poetry books. They are a group of distinguished versifiers, with an important network of social and cultural relations, in a common material space and with a general propension to print. Their activity and works sketch the development of the process of creating poetry books.

Mots-clés : Imprimerie - Édition - Livre de poésie - Saragosse - Moncayo - Díez y Foncalda - Navarro - Alfay - Torre Sevill - López de Gurrea.

1. El presente trabajo forma parte del proyecto «La poesía del periodo postbarroco: repertorio y categorías", FFI2008-03415/FILO del Plan Nacional de Investigación Científica, Desarrollo e Innovación Tecnológica.

Bulletin Hispanique, Tome 113, n 1 - juin 2011 - p. 69 à 101. 
BULLETIN HISPANIQUE

\author{
Para François Lopez, \\ que nos abrió caminos, \\ también sobre el tiempo de los novatores
}

$\mathrm{N}$

o se atravesaba el ecuador del siglo XVII en el mejor de los escenarios posibles para el trono de la Monarquía Hispánica. En la fase final de su reinado Felipe IV veía multiplicados los signos de la decadencia y el ocaso, que no habrían de encontrar respuesta bajo el cetro de su sucesor, el malhadado Carlos II. Desde el aplazado intento de unión de armas (1626) por parte de Olivares y los primeros resultados de su agresiva y beligerante política exterior hasta el inicio de la sucesión de derrotas abiertas en Rocroy y la definitiva caída del valido, un encadenamiento de acontecimientos conduce inexorablemente a una situación de declive que, si bien resulta incuestionable para el imperio y aun la idea de España, deja al resto de los reinos peninsulares en una paradójica situación de perspectivas algo más halagüeñas, aunque no exentas de conflictos y amenazas. Así, John Elliott ha podido afirmar que «la segunda mitad del siglo XVII fue realmente para la Monarquía la edad de oro de la autonomía provincial, una edad de respeto casi supersticioso hacia los derechos y privilegios regionales por parte de una Corte demasiado débil y demasiado tímida para protestar» ${ }^{2}$. La situación tiene particulares reflejos y matices propios en la corona de Aragón y, sobre todo, en su epicentro, la capital virreinal de Zaragoza. Aún respirando por la herida abierta a causa de los sucesos relacionados con Antonio Pérez bajo el reinado de Felipe II y las alteraciones posteriores, la ciudad y el conjunto del reino se agitaban bajo una creciente toma de conciencia de su distinción y el fuero político que la reconocía, así como con la correspondiente inclinación a convertir las manifestaciones culturales en expresión de ese estado de cosas y en cauce para su modificación. Entre los vínculos con Castilla y el trono, de una parte, $y$, de otra, la presión resultante de la revuelta catalana, aun tras el retorno de sus protagonistas a la disciplina del trono, la capital zaragozana vive con intensidad la búsqueda para formular o redefinir su propia identidad, en un momento en el que, además, se está produciendo una amplia y profunda fractura, desde el modelo epistemológico a la manifestación estética que aunamos bajo el rótulo de barroco. Con los polos de las élites locales y la corte virreinal, la práctica poética o, en términos más amplios y exactos, el ejercicio del verso discurre entre las pervivencias de los

2. John H. Elliott, La rebelión de los catalanes (1598-1640), Madrid, Siglo XXI, 1977, p. 483. Véase también John H. Elliot et al., 1640: la Monarquía Hispánica en crisis, Barcelona, Crítica, 1992. 
modelos académicos, la afirmación de círculos cultos de nuevo cuño y la emergencia de formas ligadas al desarrollo comercial. De ello dan cuenta, respectivamente, el auge de justas y certámenes, junto a la proliferación de círculos poéticos de cierta regularidad ${ }^{3}$, donde se aúnan la consolidación social, la visibilidad del poder y el protagonismo de élites; la proliferación de textualizaciones de la efectiva realidad de los grupos culturales y poéticos, con modelos tan dispares como la miscelánea impresa por Alonso Bondía y el manuscrito catálogo de Ustarroz $z^{4}$, u otra forma de vínculos proyectados en los textos de manera más sutil, como se manifiesta en los tratados de Gracián, en especial en la Agudeza y en algunos de los episodios de $E l$ Criticón; y, finalmente, la actividad de Alfay en su compleja dimensión de impresor, librero y promotor de antologías, como manifestación más acabada de la paulatina presencia de imprenta y mercado editorial en la fijación de todas estas modalidades discursivas, con lo que ello conlleva de proyección más allá de los estrictos límites locales, entre el foco de la corte y el amplio escenario nacional de lectores. A grandes rasgos, tales son algunos de los componentes del marco en el que se produce una singular proliferación de ediciones poéticas en un entorno definido, que bien puede operar como verdadero microcosmos, con una intensidad que convierte en reveladores muchos de sus componentes como representativos de los procesos que la poesía española comenzaba a manifestar para estas fechas y vivirá de manera más patente en las décadas siguientes.

3. Para el mundo de los círculos académicos, sigue siendo un estudio básico el de José Sánchez, Academias literarias del Siglo de Oro español, Madrid, Gredos, 1960, aun con sus carencias: en algún caso, como el relativo a la academia zaragozana del conde de Lemos, reiteradamente aludida en estas páginas, las únicas noticias que aporta son las extraídas de los vejámenes publicados en algunos de los libros que vamos a considerar, en concreto los de Moncayo y Navarro.

4. Ambrosio Bondía, Citara de Apolo y Parnaso de Aragón, Diego Dormer, Zaragoza, 1650; con edición reciente de José Enrique Laplana, Institución Fernando el Católico / Instituto de Estudios Altoaragoneses, 2000. Y Juan Francisco Andrés de Ustarroz, Aganipe de los cisnes aragoneses celebrados en el clarin de la fama, impreso en Amsterdam, 1781, y reimpreso en Zaragoza, 1890, sin haber conocido ediciones posteriores; para el contexto de este repertorio de ingenios, antecedente de bibliografías como las de Nicolás Antonio, véase Ricardo del Arco y Garay, La erudición española en el siglo XVII y el cronista de Aragón Andrés de Ustarroz, Madrid, CSIC, 1950; y, de manera más específica y actualizada, Ma Carmen Marín Pina, "Juan Francisco Andrés de Ustarroz y el Parnaso femenino de Aragón", Bulletin Hispanique, 109, 2, 2007, p. 589-614. 
Tras la aparición de la Cítara de Apolo de Bondía, en el eje del siglo, la primera entrega de la imprenta poética zaragozana ${ }^{5}$ la constituyen las Rimas de Juan de Moncayo, marqués de San Felices, rasgo éste que no deja de ser pertinente. La obra, de título tan escueto como significativo, es un perfecto síntoma de un doble proceso de transición de viva actividad en estos años. De una parte, en lo que pudiéramos llamar la "historia interna» de la poesía, asistimos al acomodo y adaptación del legado de la tradición poética que atraviesa, desde las Rimas de Lope, el siglo XVII, proyectando un modelo de base petrarquista en continuo estado de renovación, junto a la pujanza de una poética gongorina que, al margen de extremismos y polémicas, comienza a calar para convertirse en el lenguaje oficial de la poesía ${ }^{6}$. En el complementario aspecto de la "historia externa» del discurso lírico la obra del aristócrata también manifiesta el perceptible desplazamiento que en estos años, a poco de la edición póstuma de los Argensola, se está produciendo desde la práctica académica y el cauce manuscrito a una creciente importancia del mercado a través de la extensión y regularización del uso de la imprenta para la poesía culta.

Los dos vectores de la encrucijada se manifiestan en el propio volumen a través de la preocupación por la disposición y el modelo editorial, que se trasluce más allá de los indicios proporcionados por los resultados materiales, con su cuidada ordenación a partir de la fábula inicial en canónicas octavas. En ese marco se inscribe la posibilidad recogida por A. Egido en su edición acerca de una editio princeps muy anterior, datable hacia 1636, justamente cuando el futuro marqués ejercía de caballero en la corte madrileńa, hecho que otorgaría un sentido muy preciso a esta entrega poética, como elemento de medro a partir del prestigio que los versos pudieran otorgar a un autor de sangre noble, pero desplazado de su entorno natural. Si esta conjetural aparición no se hubiera producido, no faltan otras muestras de la preocupación de Moncayo por la reescritura, como las que manifestará años después en el prefacio de su Poema trágico, al confesarle al lector que «si en ésta consiguiere el logro de tu gusto, limaré las que en mis Rimas te presento con otras que la Idea borronea de nuevo»" ${ }^{7}$ no sólo muestra la

5. Véase Apéndice 1, con los pertinentes datos bibliográficos. A él remiten todas las referencias a ediciones que aparezcan abreviadas en el cuerpo del texto. Salvo que se indique otra cosa, cito siempre por las ediciones originales, modernizando grafías y puntuación.

6. Sigue siendo obligado citar para lo relativo a este entorno la obra básica de Aurora Egido, La poesía aragonesa del siglo XVII (raíces culteranas), Zaragoza, Institución Fernando el Católico, 1979; asimismo, es muy ilustrativa la consulta de su edición de la obra de Moncayo, Madrid, Espasa Calpe, 1976.

7. Es llamativa la combinación en un texto de estas características de dos conceptos en 
insistencia en la frecuentación de los moldes tipográficos, ya que igualmente expresa es su voluntad de revisar y actualizar las anteriores entregas, con la aceptación del lector como uno de sus referentes. Al mismo objetivo, aunque con un criterio más selectivo, parece atender el procedimiento que se intuye tras los sonetos de Ustarroz insertos en los preliminares: junto a la habitual función laudatoria del poeta y de apoyo y defensa de la obra, el cronista de Aragón manifiesta expresamente en un caso («restituyéndole al señor marqués de San Felices su Fábula de Júpiter y Calixto») y probablemente en otro («Vuelven, señor, las elocuentes flores / de tantos epigramas ingeniosos, / sacros, líricos, tristes, amorosos, / llenos de locuciones y primores») que los textos de Moncayo han pasado previamente por sus manos, con toda seguridad para solicitar su parecer, como constituyera práctica habitual en algunos autores, con Góngora como referente destacado. Precisamente al cordobés o, mejor dicho, a la edición más fiable y autorizada de sus poemas, sigue Moncayo en el punto de elección dispositiva para sus Rimas, donde prima la organización por metros, tal como justificara Chacón al componer el códice gongorino.

Junto a esa preocupación autorial por el efecto de sus versos a través de una edición cuidada, se aprecian los temores derivados de la entrega del volumen a los lectores, menos por la incertidumbre de la acogida que por la resistencias que aún en esos años, y más cuando quien lo hace es un miembro de la nobleza, se mantienen hacia la impresión de los poemas. La propia elección de la dispositio y el uso del lenguaje gongorino pueden ser las primeras de estas estrategias de justificación, pues no en balde la lengua del cordobés se estaba convirtiendo en esos años en el patrón del estilo poético culto y sublime, como ha señalado Jesús Pérez Magallón ${ }^{8}$. Pero no es esto lo primero que percibe el lector, pues para llegar a los poemas de Moncayo ha de atravesar un elaborado entramado paratextual que comienza desde la propia portada.

expansión en el siglo XVI, como "gusto» e «Idea», aparentemente pertenecientes a registros distintos de la poética, más popular y barroca la primera, más aristocrática y manierista la segunda, pero ambas caracterizadas por la franca superación de los estrechos límites del neoaristotelismo y su apertura hacia las formas modernas; véase al respecto Francisco Sánchez Blanco, "Los comienzos de una estética del gusto español en el Renacimiento», Revista de Literatura, LI,102, (1989) 395-409; y David H. Darst, Imitatio. Polémicas sobre la imitación en el Siglo de Oro, Madrid, Orígenes, 1985. Para la relación entre práctica editorial y conciencia de autor puede consultarse P. Ruiz Pérez, La rúbrica del poeta. La expresión de la autoconciencia poética de Boscán a Góngora, Universidad de Valladolid, 2009.

8. «Góngora y su ambigua apropiación en el tiempo de los novatores», Criticón, 103-104 (2008), monográfico La literatura española en tiempos de los novatores (1675-1726), ed. Alain Bègue y Jean Croizat-Viallet, pp. 119-130. 
En ella destacan

$$
\begin{aligned}
& \mathrm{RIMA} \text {; } \\
& \text { DE DON IVAN } \\
& \text { DE MONCAYO, } \\
& \text { I GVRREA,CAVALLE- } \\
& \text { RO DE LA ORDEN DE } \\
& \text { SAN.T.IAGO, } \\
& \text { MARQVES DE SAN FELICES. } \\
& \text { DEDICALAS } \\
& \text { AL EXCELENTISSIMO } \\
& \text { SEŇOR DON PEDR O FERNANDEZ } \\
& \text { de Caftro, Conde de Andrade, i Duque de } \\
& \text { Taurifano. Primogenito del Excclentifsimo } \\
& \text { Seños Conde de Lemos, ide Caftro, } \\
& \text { Virrei, i Capitan General del } \\
& \text { Reinode Aragon. }
\end{aligned}
$$

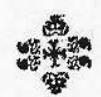

Figura 1. - Juan de Moncayo, Rimas, Zaragoza, por Diego Dormer, 1652.

los aristocráticos apellidos del autor, su condición de caballero y su título de nobleza, evidenciando que el comprador no se halla ante un producto vulgar, por más que el resto de los elementos, desde el título stricto sensu a la composición tipográfica emparenten el volumen con los habituales en su género. No lo es tanto la persona del destinatario, hijo del conde de Lemos y, de manera más específica y determinante en el contexto del autor, capitán general del reino de Aragón. La referencia se mantiene de manera constante en el cuerpo del volumen, ya que el encabezamiento, a doble página, en todos los pliegos a partir de los preliminares es el de «Rimas del marqués / de San Felices», de forma que el lector nunca pierda de vista la condición real del autor, por más que pueda verse arrastrado por el estatus lírico y lo genérico de los versos. Finalmente, y ello es aún más significativo por lo que implica y por la continuidad en los volúmenes de los ańos sucesivos, en el conjunto del volumen aparecen textos o menciones de diferentes autores, que conforman 
un verdadero "parnaso aragonés», un grupo de autores con nombre propio $y$, en gran medida, con obra que ha pasado o pasará a la imprenta en los años inmediatos; es el caso de Manuel de Salinas, de Díez y Foncalda, de Josef Navarro y de Funes Villalpando, entre los poetas, Ustarroz, de producción general en prosa, y, junto a ellos, otros, como Juan Orencio de Lastanosa, Josef de Moncayo, Miguel Leonardo de Argensola, Francisco Diego de Sayas Ravaneda, Silvestre Cabrera, Francisco de Bustamante, Gaspar Agustín, Juan Francisco de Ágreda, Jorge Laborda, Juan Antonio Rodríguez y Martel o Juan Jaime Esporrín, todos ellos adornados con el título de «don» y coronados por el soneto del conde de Torres. Esto es, se trata de un parnaso prestigiado por sus versos, pero también por el lugar de relevancia social que ocupan. Tras dos dobles pliegos y medio, el lector sólo puede acceder al primer texto de Moncayo deslumbrado por la aureola de alabanzas y relaciones que rodea al autor, propiciando la recepción y aceptación de su obra.

La reaparición de muchos de estos nombres en el mismo contexto en las ediciones que siguen muestra lo sistemático de la práctica y el mantenimiento de una tramada red de relaciones, prueba de la consistencia del grupo y de su voluntad de autorrepresentación a manera de auténtico parnaso, también en el espacio de la página impresa. A ella llegan desde las manifestaciones de la poesía pública, que precede a la publicada. Es el caso de la "Introducción a una academia» ${ }^{9}$, que Moncayo traslada a su volumen desde su original contexto; compuesta en una silva de pareados, incluye, en octavas, un parnaso descriptivo, donde se aúnan armas y letras y se incluye a un buen número de nobles y a bastantes de los versificadores presentes en los preliminares. De ellos afirma «Éstos los héroes son por quien el Ebro / (...) / se corona de lauros y corales», para concluir que "hoy traslada Helicona / al Ebro del Parnaso la corona». La presentación de parnasos como estos "cisnes de la Mantua Carpetana» se estaba convirtiendo en reiterado recurso de la pluma (y el buril) en un contexto a la vez de exaltación de la poesía lírica y de consagración de un canon moderno y nacional, pero también como el marco en el que se podían desplegar las estrategias de justificación o de exaltación autorial ${ }^{10}$. No faltaron ejemplos de muy dispar condición

9. Páginas 94-107. La academia fue presidida por Moncayo y tuvo lugar precisamente «en casa del excelentísimo señor conde de Lemos», tan presente en todo el volumen.

10. Ya realizó una llamada de atención sobre el particular Julio Vélez Sainz, El parnaso español: canon, mecenazgo y propaganda en la poesía del Siglo de Oro, Madrid, Visor, 2006. En un contexto más sitemático se inscriben los estudios del Grupo PASO sobre la materia: En torno al canon: aproximaciones y estrategias, Universidad de Sevilla, 2005; El canon poético en el siglo XVI, Universidad de Sevilla, 2008; y El canon poético en el siglo XVII, Universidad de Sevilla, 2010, dir. Begoña López Bueno; y El parnaso versificado. La construcción de la 
en el entorno aragonés, cuyos protagonistas fueron muy activos en esta autorrepresentación colectiva. Así, aparecieron en la pluma de cronistas y eruditos, de polemistas, de tratadistas y de poetas, con nombres significados como los de Ustarroz, Cebrián, Sayas, Pellicer o el propio Gracián, tanto en forma de series regulares y enumeraciones ordenadas, como en una constelación de nombres salpicados de forma heteróclita en el texto o en el volumen. No es extraño que, en el contexto de la política de Olivares, junto a intentos como el de Tamayo de Vargas para conformar una bibliografía nacional hispana, en su Junta de libros ${ }^{11}$, aparecieran elementos de respuesta o de particularismo, convirtiéndose los parnasos regionales o locales en una forma de diferencia frente a la pretendida unificación propugnada desde la política castellana, pero también para buscar una conciliación o un punto intermedio entre las extendidas prácticas de mercado editorial en una corte que se está erigiendo en centro del campo literario y unos hábitos que ya resultan arcaizantes, propios de una aristocracia culta en la periferia geográfica y sociocultural de la península, articulada en cortes nobiliarias o proyectada en los moldes académicos de las élites urbanas. Entre los avatares de la historia y la dinámica propia de la práctica poética, casi en el eje del siglo y en el marco de una corte virreinal y centro editor en apogeo, el libro de las Rimas de Moncayo, con su aderezo de participantes y concurrentes, nos plantea tres núcleos o elementos de reflexión, confirmados por la reiteración de circunstancias en las ediciones de algunos de los poetas presentes en el volumen de 1652 .

El primero de estos puntos es el relativo a la dimensión colectiva, al carácter grupal manifiesto en la presentación de estos autores, un rasgo que se traba primero en las relaciones personales o, más bien, estamentales, como parte del patriciado urbano y la minoría culta, para proyectarse a continuación en una cierta consonancia estilística; sin responder a un programa expreso, nos hallamos con la lógica manifestación de una compartida concepción de la poesía y su lugar en el marco social, por más que, dentro del correspondiente sentido del decorum, se despliegue en una variedad de registros elocutivos, que van desde lo burlesco al sublimis, pasando por el concepto y la erudición; aunque sin los límites impuestos en el marco de la cultura manuscrita, el carácter centrípeto de estas relaciones tiende a mantenerlas en un entorno local o regional, cuando no incurre en el localismo, por más que no sea éste el caso de Moncayo y la mayor parte de los autores que lo acompańan. En

república de los poetas en los Siglos de Oro, dir. Pedro Ruiz Pérez, Madrid, Abada, 2010.

11. Hay edición reciente: Tomás Tamayo de Vargas, Junta de libros, ed. Belén Álvarez García, Madrid, Iberoamericana, 2008; véase también P. Ruiz Pérez, «La Junta de libros de Tamayo: bibliografía, parnaso y poetas», Bulletin Hispanique, 109, 2, 2007, pp. 511-543. 
segundo lugar encontramos cómo la adscripción de la práctica totalidad de los poetas de este grupo a las élites o sus espacios de manifestación orienta el ejercicio del verso, aun cuando pase por los moldes de la imprenta, a una precisa definición de su lugar social, cultural y poético, manteniendo un aristocratismo que ya no es cuestión de dificultad docta, sino más bien de desenfadada práctica de lo que se presenta como un producto del ocio entre saraos cortesanos, sesiones de academia y fiestas de exaltación local, civil o religiosa; el resultado es una reorientación de la poesía muy alejada del intimismo expresivo o de la empresa personal de construcción de un mundo a través del lenguaje, como venía ocurriendo desde la innovación garcilasiana. Finalmente, se percibe el papel que en toda esta dinámica comienza a desempeñar el libro impreso, con su específica codificación y los mecanismos pragmáticos que pone en funcionamiento o, mejor dicho, a los que da cuerpo, y en ello tiene un doble papel el componente editorial que conlleva la composición de todo libro de poesía: la articulación de la variedad en la unidad y el paso de lo procedente de una concreta situación pública o privada, entre la plaza pública y el salón señorial, a una condición publicada, con una multiplicación de ejemplares que, al trascender los límites del contexto original, convierten la obra más culta en algo vulgarizado, por divulgado.

Muy posiblemente estos tres factores apreciables en la obra de Moncayo estén indicando otras tantas líneas de desarrollo en la poesía de las décadas siguientes y serían de utilidad para establecer una lectura crítica e interpretativa del género en el período del bajo barroco. Lo que es incuestionable es su peso en la poesía aragonesa de los años siguientes, incluso en autores con una posición social bastante distante de la ocupada por el marqués de San Felices. Así se aprecia, por ejemplo, en las palabras con que Jorge Laborda, "amigo grande del autor», introduce apenas dos años después del volumen de Moncayo el de Josef Navarro ${ }^{12}$; en el texto "Al que leyere», sintomático de la recepción indiscriminada que esperaba al libro impreso, Laborda afirma:

Arduo y difícil se ofrece el primer empeño de cualquier empresa, y pocos hay que cuesten más honrados temores que dar un escritor su primera obra a la estampa, y más las de poesía, por ser tan general la presunción de muchos, que no quieren entender que no la entienden (...). Quien saca un libro a la luz la de los estudiosos solicita, porque en ella se ilustran los desvelos, y a su sombra se disimulan los descuidos

12. Y no está de más insistir en que estos dos nombres aparecían en los preliminares de las Rimas de 1652. 
leves; mas los que viven desalumbrados de la ciencia, dormitando en las tinieblas de la ignorancia, imaginan a escuras, discurren a ciegas y, finalmente, increpan sin tiento.

La reserva ante jueces y lectores deja paso de inmediato a la referencia a una preocupación más relacionada con la propia labor del poeta y la justificación de la variedad que caracteriza a estos volúmenes:

La naturaleza crió entre lo profundo de los valles lo descollado de los montes; en lo diáfano de los cielos, mayores y menores las estrellas; luego a imitación de la naturaleza y del arte no será defectuosa la desigualdad de los versos.

Lo significativo, más aún que el hecho de que los poetas venzan esos temores y que se apoyen mutuamente en la justificación de su osadía, es lo sistemático con que a lo largo de una década en Zaragoza los poetas se entregan a la publicación de sus versos en libros unitarios, en una condensación de títulos con muy escasos precedentes. Entre 1652 y 1663 (véase Apéndice 1) son 10 los volúmenes poéticos de autores de Zaragoza o en ella asentados publicados en los talleres de la ciudad, uno más si tenemos en cuenta el de Francisco de la Torre y Sevil ${ }^{13}$; a ellos cabría sumar las ediciones del cordobés Colodrero Villalobos y la del murciano Polo de Medina, y no habría que olvidar la edición de Cáncer y Velasco en Madrid, en 1651, que se convertirá en un factor de importancia para este despliegue. Entre los títulos se halla alguno de carácter misceláneo, así como alguna fábula o epilio, esto es, libros con poemas y poemas-libro, pero lo dominante es la presencia de libros de «rimas» o "varias poesías», siguiendo el modelo ampliamente consagrado desde finales del siglo anterior: seis de los títulos ${ }^{14}$ pertenecen a esta categoría, y todos ellos la ostentan de alguna manera en la rotulación de su portada, siete si sumamos el volumen de Cáncer, reeditado en esa década y otra vez en 1675 .

La concentración editorial resulta aún más relevante en contraste con el panorama del medio siglo precedente, donde sólo se registran en

13. El poeta tortosino permaneció algunas temporadas en Zaragoza y trabó estrechas relaciones, que se manifestaron en una nueva presencia del "parnaso aragonés» en su volumen. Se recogen las noticias sobre el autor en la tesis doctoral de Enric Querol Coll, Cultura literaria en Tortosa (siglos XVI y XVII), Universidad Autónoma de Barcelona, 2005.

14. Me refiero a los de Moncayo, Díez de Foncalda, Navarro, Alfay, de la Torre y Sevil y López de Gurrea, en los que me centraré más específicamente en estas páginas, aunque teniendo en cuenta la serie que completan los restantes títulos publicados. 
las prensas zaragozanas 43 ediciones de libros de poesía (en un sentido amplio; véase apéndice 2), recogiendo 35 títulos, esto es, bastante menos de 1 por ańo, y concentrados todos en 11 impresores. En conjunto, se trata de aproximadamente un $5 \%$ del total de títulos surgidos de las prensas zaragozanas $^{15}$, que suman 924 impresos registrados. Analizando la naturaleza de las obras en verso editadas en la Zaragoza de la primera mitad de siglo encontramos una amplia presencia de reediciones y antologías, de mucho romancero y abundantes actas de certámenes y academias, sin que destaquen los volúmenes de composiciones líricas de carácter profano de un único autor, lo que en sentido estricto podríamos denominar «libro de poesía». En definitiva, lo que encontramos es la sanción tipográfica de unas obras en verso concebidas para su realización en la oralidad o para mantenerse en ámbito de los cartapacios, y que saltan a las letras de molde tras confirmar su éxito en esos campos, casi siempre con carácter póstumo. Las obras de algún relieve (Argensola, Rey de Artieda, Dicastillo y Colodrero) son las que escapan de una u otra forma a las marcas de este panorama y, en algún caso, se trata de autores ajenos al entorno zaragozano o aragonés, como el valenciano Rey de Artieda o el andaluz Colodrero; los Argensola, además, sólo aparecen con carácter póstumo. En cuanto a los impresores, destaca la continuidad de Diego Dormer y Pedro Lanaja antes y después del medio siglo, siendo los talleres en los que la proporción de obras líricas fue de las más elevadas en el conjunto de la producción, de la misma manera que hay que resaltar el papel que ya a partir de 1653 juega Juan de Ybar, como participante muy directo en la eclosión de ediciones líricas de la década.

En la comparación entre las dos etapas, la de la primera mitad de la centuria y la de la década señalada, encontramos que la producción de obras líricas impresas se duplica, que se extiende el formato de "libro de poesía», que se multiplica exponencialmente el protagonismo de autores «locales» vivos y que en éstos predomina el carácter culto, con un fuerte peso de la imitación gongorina, con un marcado carácter académico $\mathrm{y}$, en muchos casos, con una directa vinculación a los círculos nobiliarios o aristocráticos. Adelantemos, pues, unas primeras conclusiones, pues, si los primeros datos

15. Recojo y tabulo los datos proporcionados por Esperanza Velasco de la Peña, Impresores y libreros en Zaragoza 1600-1650, Zaragoza Institución Fernando el Católico, 1998, exhaustiva continuación de la labor emprendida más de un siglo antes en la obra pionera de Gerónimo Borao, La imprenta en Zaragoza (1860), ed. facsímil Vicente Martínez Tejero, Zaragoza, Ibercaja, 1995. Puede consultarse también Inocencio Ruiz Lasala, La imprenta en Zaragoza, con noticias de las de Barcelona, Valencia y Segovia, Zaragoza, San Francisco, 1975, en particular sus observaciones sobre el auge de la imprenta en el siglo XVII, con más de 50 impresores registrados, vinculado al desarrollo de la Universidad y la Diputación en la ciudad. 
se enmarcan en una apertura de la labor de las imprentas y la expansión del mercado, incluyendo al libro poético, los dos últimos tienen que ver directamente con un cambio apreciable en la actitud de los poetas, frente al modelo representado, en ese entorno, por los Argensola, y lo hacen en un grupo en el que el factor de la profesionalización no es el determinante, dada su adscripción al patriciado urbano, entre la nobleza de la sangre y la de la cultura, incluso practicantes en algún caso, como el de Francisco de la Torre y Sevil, de la labor de mecenazgo. Sin duda, se trata de cambios de trascendencia y que entran en directa relación con la conformación del «libro de poesía» que se impondrá de manera irreversible en los años siguientes, como una de las aportaciones de trascendencia del período bajobarroco.

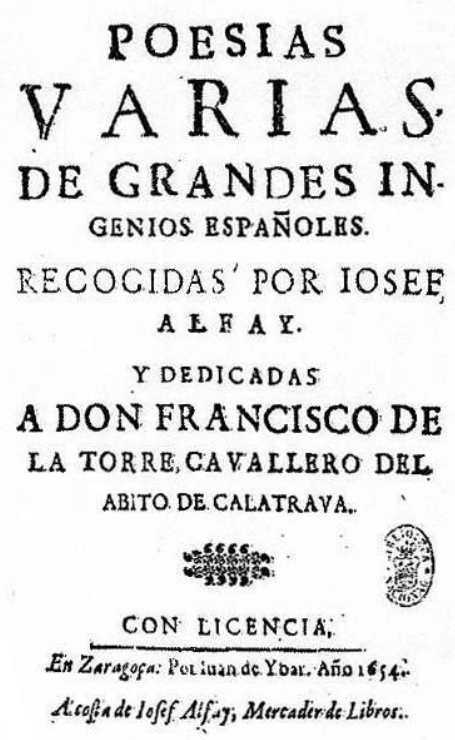

Figura 2. - Josef de Alfay, Poesias varias de grandes ingenios españoles, Zaragoza, por Juan de Ybar, 1654.
POESİAS

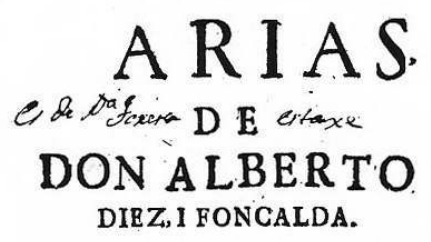

PRIMERA PARTE.

DEDICADA

AL EXGELENTISSIMO

SEÑOR DON ANTONIO PIMENTEL; Conde de Benayente, i Luna, Duque, $\mathrm{i}$ Marques,

8c. Gentilhombre de la Camara de fu Mageftad, i Comendactor de Socoss cataOrden de Sant-lago

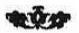

CON 2 ICENCIA

En Zarzagoça, Por Inand de Ybar, Aạ́o M.DC.LIII.

Figura 3. - Alberto Díez y Foncalda, Poesías varias, Zaragoza, por Juan de Ybar, 1653.

Una de las piezas que puede servir de hito de referencia en el giro adoptado por la poesía, las Poesias varias de grandes ingenios españoles, es una de las más singulares de la serie zaragozana de la década de los cincuenta, al tratarse de una antología, de amplio alcance en la selección de textos y autores, ya 
que, aunque hay una notable presencia de los del entorno más inmediato en el tiempo y el espacio, se incluyen textos desde finales del siglo XVI y procedentes de la más variada geografía peninsular. Casi medio siglo después de la empresa de Espinosa con las Flores de poetas ilustres de España, es ahora un librero quien asume la iniciativa de una nueva antología, en este caso con menos pretensiones de novedosa aportación estética que de éxito comercial, es decir, justo lo contrario de lo acontecido con la selección que el antequerano dio a la luz en la corte vallisoletana. Si éste apuntaba a la selección («Flores», «ilustres», la retórica prologal...), Alfay se dirige sin ambages a objetivos comerciales, apostando por textos que ya habían probado su recepción, amparándolos bajo rótulos en boga («poesías varias», «ingenios») y obviando el cuidado tipográfico, pero buscando el amparo de la figura de prestigio, que podía tender un puente entre los dos extremos, el de la poesía culta y el de la difusión popular, reuniendo en la expresiva dedicatoria una parte sustancial de los rasgos apuntados, a falta de la lógica reducción al ámbito local y la no menos esperable mezcla de lo culto con otros registros; sí es muy evidente la estrecha relación de esta iniciativa comercial con lo señalado respecto a la apertura de este ámbito en los moldes de la imprenta. La argumentación de la dedicatoria, que bien merece una reproducción completa, es reveladora de la búsqueda de equilibrio por medio de elementos reconocidos, para avalar una empresa con mucho de novedosa:

A don Francisco de la Torre, caballero del hábito de Calatrava

$\mathrm{Ni}$ sé si de agradecido o interesado ofrezco a v.m. estas poesías, porque, deseando sacarlas a la común luz para ingenioso entretenimiento de entendidos, siendo mi fin el que se reciban gustosamente, su protección de v.m. me las acredita, pues no rozarán ellas (por ser de los mejores ingenios de España, y algunas del de v.m., que es lo mismo) el aplauso que su crecido talento y bien logrados estudios tienen merecido, como en el Teatro de la Fama, en el de esta ciudad, ya ocupando en lo cómico de víctores la admiración, ya en mayores obras la esperanza a los deseos que con ansias de buen gusto aguardan que v.m. las dé a la inmortalidad, como único Fénix catalán, hijo de la fidelísima y ejemplar ciudad de Tortosa, siendo el que solo en aquella nación se ha apropiado las voces castellanas con tanta gala y acierto, y así habré yo con esta diligencia conseguido el fin de mi agradecimiento a las muchas honras que le debo. Róbole a esta dedicatoria lo que a todas hace grandes, que es delinear la ilustre ascendencia del mecenas, pero, porque esta no pase a grandísima, callo la de v.m., pues, por muy conocida, fuera osadía de mi poquedad 
atreverme a su narración, y v.m., por enemigo de tales aplausos, se me desabriera, deseándolo para amparo de esta obrecilla gustoso. Dígnese v.m. de esta ofrenda, para que ella quede con el lustre que necesita contra la mordacidad del vulgo, y yo saque el coste siquiera de haberla impreso, pues espero que me ha de hacer la costa no más de verse acreditada del patrocinio de v.m., cuya vida dilate el cielo muchos siglos.

La llamativa combinación de elementos de la más rancia escuela con una práctica efectiva de plena modernidad es reveladora del estadio de transición en que se encuentra la poesía en este momento, o, más exactamente aún, si nos situamos en la perspectiva de su historicidad, de la encrucijada que se abría ante las miradas más inquietas. No menos reveladora lo es de un aspecto que tiene mucho que ver con esa ambigua y compleja situación, como es la convivencia, si no complicidad, mantenida en un contexto de límites difusos, por parte de distintas posiciones de campo, que comienzan a neutralizarse justamente por la frecuentación de la imprenta. Valga adelantar en este punto cómo el apelado como mecenas y protector no tarda en bajar personalmente a la palestra de la edición, ofreciendo su Baraja nueva de versos el mismo año y, no es baladí, en la misma imprenta que la antología de Alfay; ambos, además, volverían a coincidir 16 años después en una empresa similar, la antología Delicias de Apolo, recreaciones del Parnaso, difundida con dos cabeceras distintas, la que desde Madrid la pone bajo la firma de de la Torre y la que en Zaragoza aparece auspiciada por Alfay, en una no del todo esclarecida relación ${ }^{16}$.

Como a despecho de la postura adoptada en la dedicatoria, en el «Prologo al letor» Alfay cambia el registro y deja atrás todas las prevenciones, y no sólo porque se muestra dispuesto a plegarse al gusto o capricho del destinatario, el futuro comprador («De los mejores poetas de España son, si te contentan, y, si no, de los más malos»); de manera explícita se dirige a él con el relativamente novedoso apelativo de "letor amigo», en abierto contraste con los irónicos, desconfiados o francamente despreciativos calificativos con que los autores de las décadas anteriores se dirigen a sus receptores. Y no sólo ellos; el ańo anterior Díez y Foncalda cierra el romance "A quien leyere», que acompańa a la dedicatoria al conde de Benavente ${ }^{17}$, con el directo vocativo

16. Un primer acercamiento puede encontrarse en P. Ruiz Pérez, «Entre dos parnasos: poesía, institución y canon", Criticón, 103-104 (2008), ed. cit., pp. 207-231. Un trabajo más detenido y específico sobre los avatares editoriales de la Delicias es el que prepara Juan Montero.

17. Al noble se dirige la primera parte del volumen, el de las composiciones profanas, 
«letor enemigo», y, entre burlas y chanzas, no muy distintas a las empleadas al dirigirse al mecenas, apela al ocio y al entretenimiento, respetando el gusto y criterio del lector, como si estuviese a punto de pronunciar las palabras que poco después Alfay no duda en escribir, señalando su voluntad de recuperar «el coste de haberla impreso». La traducción en el «Prólogo al letor» del antólogo es una justificación de la variedad por la heterogeneidad de lectores y gustos, con la promesa de ampliar el volumen si la primera entrega es aceptada. Entre el negocio declarado, el de Alfay, y el ocio invocado, el de Díez y Foncalda, las diferencias comienzan a neutralizarse. De hecho, el académico Foncalda no es ajeno al papel de los libreros, y la ocasión de satirizarlos no debe de ser ajena a una experiencia más o menos directa; así lo pone de manifiestos en las redondillas «A una comedianta que la solicitaba un librero»:

¿No acabas ya de obligarte?

¿Cómo a Fabio no te ajustas?

Si de su cuerpo no gustas, dos mil cuerpos puede darte.

Vivirás muy bien hallada, que es hombre de los más buenos; está rico, y, por lo menos, no andarás descuadernada.

Lo que su ingenio dispone todo es invención y tretas; se ríe de los poetas porque él sus libros compone (...).

Si a esta conciencia de la "composición» de los libros debida a los libreros sumamos lo que, burla burlando, implica el reproche contenido en el soneto

mientras que la segunda, con composiciones religiosas y morales, se dedica al obispo de Jaca. Nótese que la relación del aristócrata con la poesía tiene su exponente más destacado en el hecho de mantener como criado a Cáncer y Velasco, quien también sirvió al conde de Lemos, en cuya casa se mantuvo academia celebrada por Foncalda, que incluye un número apreciable de poemas con el rótulo «fue asunto de academia». En la aprobación del volumen el licenciado Juan Francisco Ginovés, autor de las «Silvas de todo el año» y responsable también de la aprobación de la antología de Alfay, insiste en la continuidad que implica ser émulo de los Leonardos y enmarcarse, pese a su tono de composiciones «seriamente jocosas», en un parnaso donde se muestran "las afluencias en los ingeniosos aragoneses», pero también en unas líneas de "poesías que de las fecundidades castellanas cada día fluyen en tomos nuevos", con una precisa mirada sobre la conjunción de academia e imprenta, que vuelve a ponerse de manifiesto en las composiciones laudatorias que siguen, por la nómina de sus firmantes y por los argumentos que manejan, en nueva figuración del canon poético en torno al Ebro (cfr. infr.). 
«Enójase el autor con una dama que el enamorarla fue causa que hiciera versos», podemos percibir el asentamiento de una conciencia de artificio para la que la poesía no se concibe como efusión y expresión sentimental, sino como la construcción de un producto destinado a un lector muy alejado ya del entorno más inmediato, el de la amada, el del amigo o el de los copartícipes de salones nobiliarios o académicos.

Con las peculiaridades propias de la posición periférica y la condición virreinal, los ingenios de Zaragoza, sin gran distinción por razones socioculturales, se van acercando, sobre todo en esta década, a las prácticas editoriales ya prácticamente consagradas en el marco de la corte, entendiendo ya en ella no el marco inmediato del trono, sino el centro de un institucionalizado mercado literario. No era un caso aislado, como muestra, por ejemplo, el ámbito granadino de los discípulos de Soto de Rojas, con Trillo y Figueroa a la cabeza, ensayando por los mismos años la acomodación de distintas fórmulas editoriales para la regularización de la poesía culta con la imprenta ${ }^{18}$; algo similar cabría señalar para Murcia ${ }^{19}$, con la lejana referencia de Cascales y el papel dinamizador de Polo de Medina, precisamente impreso en Zaragoza en estos años. La extensión del proceso por escenarios tan diferenciados es un índice inequívoco de los cambios que se están produciendo en los usos y en la consideración de la poesía, que regulariza su cauce en el libro publicado al mismo tiempo que intensifica su carácter de manifestación pública, lo que le otorga un carácter muy singular al libro de poesía bajobarroco, muy lejos de la organicidad y confesionalismo del modelo cancioneril petrarquista, pero también de la modalidad de «rimas» impuesta por Lope, tanto en su primera entrega como en los comprometidos volúmenes de La Filomena y La Circe ${ }^{20}$. Volviendo

18. El autor gallego afincado junto al Darro, además de prologar el Paraíso cerrado de su maestro, dio a la imprenta en sistemática e ininterrumpida sucesión un poema épico, varios pliegos cultos de carácter panegírico, uno de ellos sólo con las anotaciones al precedente, y un volumen de varias rimas, en una actitud ya muy distante de la de los poetas cultos inmediatamente anteriores. Me acerco a esta peculiaridad en «El sistema de los géneros poéticos en Francisco de Trillo y Figueroa», Glosa, 2, 1991, pp. 289-306; «El poema panegírico de Trillo y Figueroa. Teoría y práctica de la renovación poética postgongorina», Hommage à Robert Jammes, Université de Toulouse, 1994, pp. 1037-49; y «Una proyección de las Soledades en un poema inédito de Trillo y Figueroa», Criticón, 65, 1995, pp. 101-177.

19. Véase la Antología de la poesía barroca murciana, ed. David López García, Murcia, Editora Regional, 1987.

20. Si en la primera edición de las Rimas, al margen de la estratégica inclusión de poemas épicos, se mantiene en la serie de sonetos una cierta continuidad con el modelo petrarquista, y no sólo por la temática amorosa, el carácter cambia por completo en las ediciones de 1621 y 1624, con un Lope volcado en su defensa y reivindicación, con un confesionalismo más 
a centrarnos en los libros zaragozanos, con el contexto en ellos reflejado, lo que percibimos es la constitución de lo que pudiéramos llamar un "campo intelectual», en el que figuras como Lastanosa, Gracián o Ustarroz representan la continuidad con los modelos académicos heredados del renacimiento, pero cada vez más proyectados a la imprenta, en tanto que de este lado se afirma cada vez con menos prevenciones o justificaciones una dimensión comercial en confluencia, tal como representa el volumen de Alfay. Las conexiones e interinfluencias de ambos polos en paulatino acercamiento denotan las estrechas relaciones entre la práctica del verso y las de los modelos y usos sociales, entre la poética y la ideología, apreciable de manera privilegiada en ese microcosmos singular formado en la Zaragoza de la primera década tras el ecuador de la centuria.

Añadamos un cuarto título a la continuidad poética de Moncayo, lo jocoserio de Foncalda y la variedad comercial de la antología de Alfay. También de 1654 son las citadas Poesías varias de Josef Navarro, cuyo prólogo «Al que leyere», que sigue a la dedicatoria a otro noble, el señor de Híjar y marqués de Alenquer, viene firmado por quien se presenta como «amigo grande del autor»; allí Laborda, junto a los argumentos ya recogidos, apela al carácter de obras de juventud y manifiesta el ánimo del autor para cosas mayores, apuntando la insistencia de los amigos como razón para imprimir, al tiempo que afirma que sería injusto dejar la obra en silencio y no buscar la fama. El desplazamiento de los tópicos de defensa a la orgullosa afirmación de deseo de notoriedad no puede ser ajeno a la extensión de un planteamiento tan novedoso, al menos en las páginas de un libro culto, si no es que comienzan ya a derribarse las fronteras entre esta categoría y la de lo popular, allanadas en el espacio de lo impreso.

moral que amoroso, con un fuerte componente metapoético y con unas claras intenciones de convertir los libros en instrumentos para el medro social. Aún sin la clave paródica y la refinada ironía, posiblemente en las Rimas humanas y divinas del licenciado Tomé de Burguillos podría encontrarse un modelo para la poesía de la segunda mitad de siglo, no tanto en la estructura de cancionero como en el distanciamiento sostenido sobre la jocosidad y el juego. 


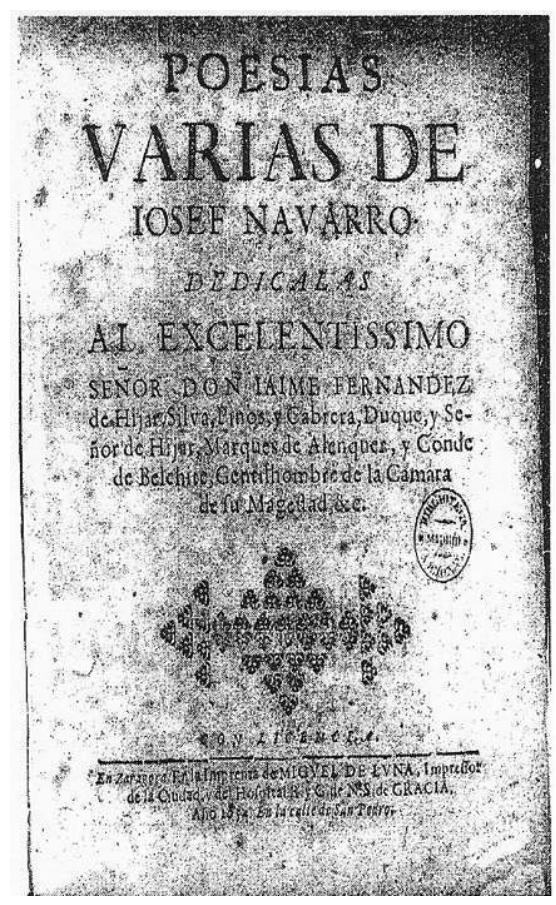

Figura 4. - Josef Navarro, Poesías varias, Zaragoza, por Miguel de Luna, 1654.

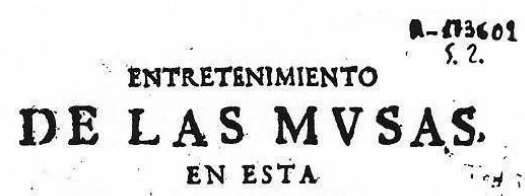

BARAXA NVEVA DE FRRSOS:-

2.9567: DIVIDIDA

EN QVATRO MANJARES, DE ASV.NIOS:

SACROS; HEROICOS, LIRICOS, Y; RVRLESCOS:

GOMPVESTA
POR EENISO DE LA TORRE, NATVRAL DE TORTOSA:

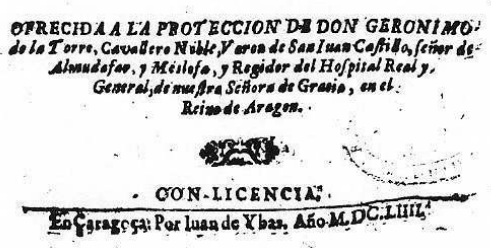

Figura 5. - Feniso de la Torre [Francisco de la Torre y Sevill], Entretenimiento de las musas en esta baraja nueva de versos, Zaragoza, por Juan de Ybar, 1654.

Algo similar ocurre con la entrega editorial de Francisco de la Torre y $S_{\text {Sevil }}{ }^{21}$, a quien hemos visto ya presentado como culto mecenas y que no duda en recurrir (seguimos en el annus mirabilis para la edición poética zaragozana de 1654) a una imagen tan popular como el juego de naipes para ordenar la variedad de sus poemas a la hora de entregarlos a la imprenta: la secuencia de palos de la baraja establece la disposición de lo sacro (oros), heroico (espadas), lírico (copas) y burlesco (bastos), pero, sobre todo, sirve para combinar el sentido de la utilidad con el deleite, imponiendo en la dualidad horaciana el sentido del juego, al tiempo que convierte la baraja, con su variable alternancia de los naipes en el conjunto del mazo, en una cumplida metáfora del libro de poesía, donde tiene su asiento la variedad de

21. Han estudiado este curioso volumen Samuel Fasquel, "Inventio y dispositio dans la Baraxa nueva de versos de Francisco de la Torre y Sevil (1654) ", Mélanges de la Casa de Velázquez, 35, 2, 2005, pp. 191-218; y, en este mismo volumen, Ignacio García Aguilar. 
composiciones sueltas, en una dialéctica entre autonomía y conjunción que se hará dominante en la lírica del período.

Tras la propuesta de Francisco de la Torre parece cerrarse momentáneamente la sucesión de entregas editoriales de similares características, siguiéndose una serie de títulos (apéndice 1) en los que se ensayan vías diferentes: la propuesta por parte de Moncayo de una fábula mitológica con extensión, entidad y altura del poema heroico, en debate por estos años, para dar con ella un ejemplo cumplido de poema-libro, cuyo modelo sigue el algo más modesto del año anterior por Funes de Villalpando; las recopilaciones de lírica sacra debidas a fray Martín de la Madre de Dios (1655) y a Colodrero Villalobos (1656), el primero un autor espiritual y doctrinal, mientras que el segundo es un poeta que sólo dedica uno de sus cuatro libros al verso sacro; y las recopilaciones de poesía jocosa de Polo de Medina (1659) y Luis Antonio (1658), el primero, ajeno al círculo zaragozano y con una obra de carácter misceláneo, y el segundo muy en la línea de Díez y Foncalda, al que le dedica el volumen. Finalmente, las Clases poéticas (1663), de López de Gurrea, cierran, algo más de una década después, la serie de poemarios abierta por las Rimas de Moncayo.

Figura 6. - Baltasar López de Gurrea, Clases poéticas, Zaragoza, por Juan de Ybar, 1663.

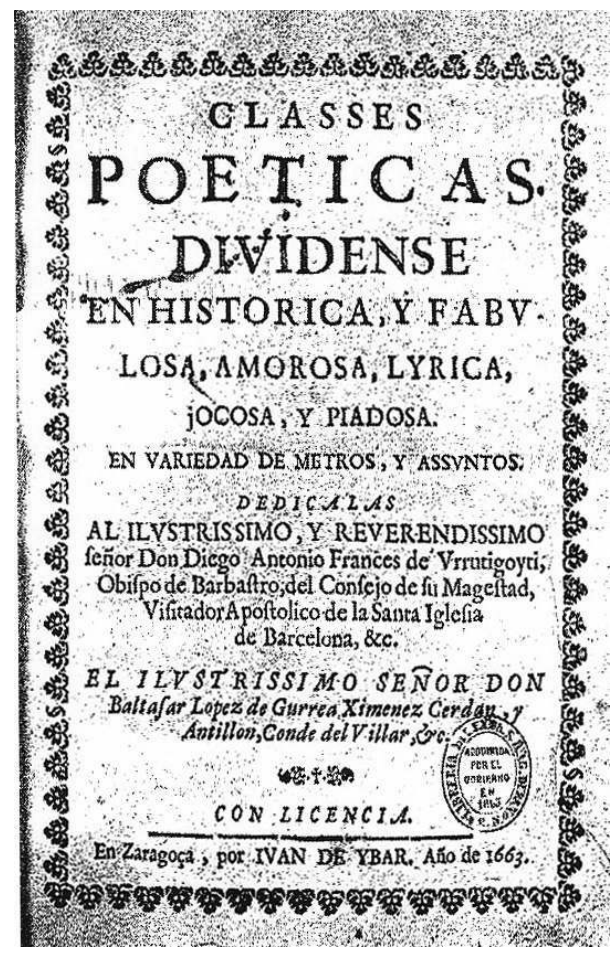


Las Clases, que debe el título al criterio clasificador, «divídense en histórica y fabulosa, amorosa, lírica, jocosa y piadosa», con una llamativa semejanza al procedimiento empleado por de la Torre y Sevil en su Baraja. En sus paratextos insiste con reiteración en el componente de variedad, y en los poemas mezcla el seguimiento del estilo gongorino con muestras de ingenio jocoso, aunque con repetidas referencias a la utilidad que se puede obtener, incluso de la materia amorosa: "Gustosa recreación del trabajo es la jocosidad proporcionada, pues da intermisión decente al laborioso estudio, que se aplica a empleos de mayor suposición y monta» ("Preludio a la clase jocosa»). El recurso a la idea humanista de la eutrapelia muestra aún las raíces de la actitud poética en el modelo precedente, pero la propia «jocosidad» apunta, además de a un rasgo dominante en gran parte de la poesía de estos años, a una línea lúdica, a las puertas de la autonomía del verso, liberado de otro tipo de pretensiones de trascendencia, tal como corresponde a las demandas del mercado, al que los poetas van a atender con progresiva regularidad.

Más allá de las similitudes y divergencias de este grupito de ediciones, la abundancia de su número es lo que nos resulta más revelador. El hecho no podría haberse dado sin la confluencia de una serie de factores, en los que podemos ver un pertinente valor historiográfico. El primero de dichos factores es la existencia misma de un colectivo de poetas, algo más que una suma de individualidades, pues se aprecia entre ellos una profusa red de relaciones, de la que cabe deducir que sus actitudes respecto a la imprenta y a la edición no responden a estímulos aislados o a intuiciones personales, sino que forman parte de un programa más o menos explícito y, por tanto, en relación con su actitud ante la escritura y ante la difusión; lo sistemático de sus apariciones públicas, los apoyos mutuos, la recurrencia de argumentos y la semejanza de realizaciones temáticas, estilísticas y dispositivas refuerzan esta impresión y contribuyen a convertirla en algo más que en una hipotética posibilidad. Pero nada de ello podría haber tenido lugar sin el segundo de los factores, la formación de una incipiente «industria» impresora y editorial, que es algo más que un conjunto de talleres y de libreros o mecenas dispuestos a sufragar la composición del libro, pues la continuidad hubiera sido imposible sin el funcionamiento de unas redes de distribución y comercialización, lo que apunta ya a un mercado del libro de poesía más o menos consolidado. Finalmente, es necesaria la concurrencia del último y, posiblemente, el más determinante de los factores, pues nada de esto se hubiera podido sostener sin la intervención activa de unos lectores, inclinados al consumo regular de poesía impresa y que, además, son previamente compradores, es decir, personas dispuestas a costear su gusto lector. 
Estamos, pues, ante una muestra de la proyección social de la poesía en su camino a la plena modernidad, con la regularización del acceso al mercado y el funcionamiento de éste como espacio de la comunicación lírica entre escritores y lectores. Lejos quedan ya los cerrados círculos cortesanos y los gabinetes humanistas, pero también esa otra forma de poesía pública constituida por las academias y sus manifestaciones sociales, en forma de certámenes y justas ligadas a la fiesta, sobre todo en su esplendor barroco. Nada de esto falta en estos volúmenes, con abundantes muestras de los orígenes de sus poemas en tales contextos, pero situados ya en otra dimensión al fijarse, no ya en la página impresa, sino en el volumen con nombre de autor, en el libro de poesía, tal como será entendido hasta la culminación de la fórmula en el simbolismo decimonónico. Como en el momento de pleno funcionamiento del "campo literario» tal como lo define Bourdieu, el autor concibe ya la recopilación de sus versos en un volumen más o menos unitario, encuentra los cauces e intermediarios para su publicación y un público que lo acoge, con la normalización de un funcionamiento en círculos amplios, que tiene que ver con un modelo social, por su dimensión comunitaria y política, en su doble sentido, el de polis, con la innegable naturaleza urbana del fenómeno, y aun el de política, al ponerse al servicio de la construcción de una identidad cultural de trascendente significado cuando estaba por redefinirse el sistema de relaciones entre los reinos peninsulares bajo el trono de los Austria.

En lo tocante al esencial carácter urbano del proceso destaca el marcado protagonismo de las élites de la ciudad de Zaragoza, con nobles de distinta alcurnia, como Moncayo, de la Torre y Sevil, Funes y López de Gurrea, y, junto a ellos, acompańándolos en distintos elementos del libro, como dedicatarios o autores de preliminares, una amplia representación de hombres de letras y miembros del alto clero, articulados en grupos que mantienen la vinculación con la «corte» académica, en ocasiones alrededor de un virrey, como el conde Lemos, en cuyo entorno se imbricaban autores de procedencia más humilde, como Navarro o Díez y Foncalda, no exentos del título de «don» y que contribuían a la complejidad y proyección del grupo, más allá de una estricta definición corporativa. Hay algo más que una identidad estamental en la repetida referencia en estos volúmenes a los "cisnes del Ebro", en paralelo a la formulación que Ustarroz dejara en su manuscrito Aganipe, con clara voluntad sistemática y consagradora de un parnaso regional. Y no son sólo las menciones directas. El rasgo se manifiesta también en la frecuencia con que aparecen motivos locales, destacando, por su número y por su importancia en la convocatoria de la actividad poética, las menciones a academias y la celebración de santos, con la esperable aparición 
de la virgen del Pilar, pero también de Bernardo y Lucía, Lamberto y los mártires de Zaragoza, Bartolomé, Agustín y Francisco, junto a la exaltación del sacramento y una recurrente celebración de las profesiones religiosas; junto a ellos ritos de la liturgia local, ocasiones de devoción vinculadas a la ciudad o alabanza de las órdenes religiosas en ellas asentadas. De lo más humano a lo más sagrado, todo lo relacionado con la religión, sus ritos, liturgias y referentes se convierte en elemento de cohesión social y de arraigo en un espacio compartido, el de una sociedad circunscrita a sus límites más inmediatos. En ella se aprietan las redes de relaciones, en un tupido haz de vínculos que se ostentan de manera llamativa y significante en el soporte impreso, convirtiendo cada uno de los títulos en una especie de carta de presentación en sociedad del conjunto del grupo. Moncayo, Foncalda y Navarro intercambian presencias en los preliminares de sus respectivos libros, en los que hacen también gala de su común pertenencia a la academia del conde de Lemos; Moncayo anima a publicar a Francisco de la Torre y Sevil, mientras que éste elogia en su Baraja de 1654 el Poema trágico de Atalanta e Hipomenes, que aquél no dará a las prensas hasta 1656, evidenciando una comunicación previa a la publicación; Alfay le dedica su antología a de la Torre y Sevil, el cual es prologado por Gracián, que a todas luces inspiró, cuando menos, las Poesías varias de grandes ingenios españoles, para volver a encontrarse los mismos protagonistas en la peripecia editorial de la antología de 1670 ya citada ${ }^{22}$; figuras como Ustarroz, Ginovés o el obispo Francés de Urrutigoyti aparecen como elementos catalizadores, con presencia en los preliminares o dedicatorias de Moncayo, Foncalda, Alfay, Navarro o fray Martín de la Madre de Dios, tendiendo puentes entre las figuras más retiradas del grupo de autores que publican en estos años; por último, la referencia al parnaso local aparece en varios preliminares, como los de Moncayo o la Baraja de versos.

La definición de este parnaso local aparecía ligada, como era tradicional, a la imagen del río, recogiendo los ecos de la imagen mítica del monte Parnaso, con sus fuentes (Castalia, Hipocrene, Crenea...) y los ríos que de ellas corrían, junto con la caracterización de los poetas como cisnes, convertida en tópica designación de los grupos poéticos. Característico del parnaso del Ebro es su continuo diálogo con el Tajo y el Manzanares, referentes del germinal Garcilaso y del núcleo madrileño que domina la actualidad poética. Así se aprecia, por ejemplo en el arranque del romance de Josef Navarro de

22. De hecho, el título con que aparece la doble emisión del florilegio de 1670 se hallaba ya completo en la aprobación (con el pseudónimo habitual de Lorenzo Gracián) del autor de la Agudeza: «He leído este libro, que se inscribe Entretenimiento de las musas, y pudiera añadir "delicias de Apolo, recreaciones del Parnaso, y los buenos ratos del gusto y del ingenio"». 
expresivo rótulo: «Anteponiendo la dicha de la Universidad de Zaragoza a las de otras ciudades, por haber merecido en sus Escuelas al excelentísimo señor cardenal D. Antonio de Aragón», y que comienza

Piélago inmenso de ciencias,
de quien son fuentes veloces
el sabio cristal de Henares,
la docta espuma del Tormes,
centro mejor del ingenio,
donde más se ilustra y donde
el más humilde se alienta,
y el más altivo se encoge,
Universidad ilustre
de la Augusta Ciudad noble
que el Ebro besa sus plantas
y el Sol corona sus torres. (...)

En este caso los ríos habituales son sustituidos por los correspondientes a las dos grandes universidades hispanas, Alcalá y Salamanca, pero las corrientes que las identifican tienen también claras relaciones con entornos o figuras poéticas, incluido el propio Garcilaso. Lo significativo es la omisión prácticamente absoluta de las referencias al Betis o, lo que es lo mismo, a los grupos poéticos andaluces, si bien es verdad que ya en estos momentos se encontraban en un estado languideciente, mientras que la alusión directa a Góngora, aun cuando se imitara claramente su estilo, seguía despertando reticencias en el fragor de una polémica aún abierta.

El entorno local, entendiendo éste en el sentido de ciudadano, corresponde a una fase, a mediados del siglo XVII, en la que a la preocupación por lo nacional, en los siglos XV y XVI, sigue una consideración de lo que está cercano al "campo literario", si no es que lo constituye ya de manera germinal. Así, superada la fase de cuestionamiento de la dignidad de la lengua romance, firmemente asentada en sus modelos, se impone la consolidación de una lengua literaria, a la que Góngora ofrece un patrón excepcional, aunque cada vez más matizado por opciones individuales a partir del apogeo del ingenio. En paralelo, a la preocupación por el reconocimiento de un parnaso nacional, con rasgos de estatismo procedentes del modelo clásico, le sigue, con sus secuelas de polémicas y enfrentamiento, la voluntad de afirmar discursos de identidad más particular, entre los rasgos de escuela y los localismos, por más que en muchas ocasiones aparezcan como facetas estrechamente vinculadas. La crisis de la Monarquía Hispánica, con la revuelta catalana y los movimientos secesionistas de Portugal, en torno a 1640, a pocos años 
del despegue editorial zaragozano, conforman un contexto muy idóneo para el auge de estas tendencias, que no se ciñen, sin embargo, a una estricta coyuntura política.

A su favor juega, en estrecha ligazón con el desarrollo específico de la poesía, la dinámica adquirida por el mercado literario, con la inclusión en el mismo del género lírico y su formalización definitiva en el formato del libro, convertido ya en el referente dominante frente a lo habitual en las generaciones previas. Ciertamente, todavía los preliminares de los volúmenes siguen siendo escenario de justificaciones y reivindicaciones, señal inequívoca de las resistencias que aún encontraba el fenómeno ${ }^{23}$, pero no es menos evidente que la tendencia se extendía, incluso recurriendo a cauces híbridos o intermedios como la miscelánea compuesta por Bondía, en cuyo prólogo resuenan los ecos de las habituales defensas del género y los argumentos para excusar la publicación:

(...) En esta obra, pues, que con recelo saco a luz y con rendida confianza la encomiendo a la prensa para la posteridad, no saco cosa nueva, sino que en el uso de la poesía y consonancias de la prosa propongo novedad de cosas conocidas, como son las sibilas y musas (...). Y si los primeros y más seguros autores se han de mirar en sentencia de Séneca (...) como dioses o cosa divina, y como a tales se ha de dar la presidencia o se les ha de pedir como a causa el celestial influjo, siendo las sibilas las primeras que con seguridad (después de nuestro padre Adán...) hablaron en metro, llenas de divinidad, no será mucho que yo las haya traído para asistencia de este Parnaso (...). Y confieso ingenuamente haberme parecido esta resolución conveniencia, por ver tan estragado el arte de la poesía, pues ya parecía ley del verso (siendo, como es, abuso y depravada costumbre) celebrar en metro cuantas liviandades y obscenidades a muchos, torpemente agudos, se les representaban, habiendo sido la poesía como producida en segundo parto (porque el primero es de Dios) dada por el Arcángel purísimo y en el mundo introducida para celebrar las cosas divinas (...) y para aclamar las humanas con hiperbólicas exageraciones (...) cuando son, por heroicas, esclarecidamente supremas. Por esta razón, cuando intenté sacar esta lectura para halago y útil deleite de los entendimientos, porque en medio de lo humano no faltase lo divino, y en lo divino se revelase lo humano, a entrambas cosas abracé y, sin desviarme de la piedad,

23. Sigo este proceso a lo largo del período áureo en los trabajos incluidos en los dos volúmenes del Grupo PASO, El canon poético en el siglo XVI y El canon poético en el siglo XVII, ed. cit. 
las traje para deleite a los campos augustos, formando mejor Parnaso, pues consta de ambas cosas. Ni para traerlo aquí me dejé llevar de la pasión y dulce afecto de mi patria, que aun a los más atentados suele hacer deslizar, sino que la conocí razón forzosa, que es lo mismo que justicia, porque si el Parnaso ha de estar donde es la materia mayor y los sujetos más, porque en nuestro reino y ciudad se verifica todo en colmo tan grande, que llega a ser admiración al Parnaso de Tracia, que fue por todo el mundo célebre, determiné trasladarlo aquí (...).

Tan extensa cita queda justificada por lo explícito de sus declaraciones y lo que tienen de representativo de un estado de conciencia respecto a la edición de versos con el que se enfrentarían a partir de dos años después los poetas zaragozanos, que manifestaron menos empacho que su predecesor en frecuentar la imprenta y divulgar sus composiciones, sin la coartada del marco narrativo o descriptivo. Al prologar la segunda entrega de Moncayo, bien que tratándose de un poema de altura y extensión heroica, Ustarroz es muy explícito respecto a esta resolución del nudo gordiano:

Y aunque es verdad que el publicar desvelos de poesía puede tener visos de ociosidad y aun parecer a muchos ocupación infructuosa, por tantos como cada día salen a la luz, sin embargo, el autor de éste que con tan primoroso arte comunica a los entendidos cumple altamente con lo que debe, siguiendo el consejo de Agustino lib. De Trinitate, que dice: «Expedit de eadem materia, fieri multos libros, quia non omnium scripta, ad omnes veniant,

Con toda la orquestación de reservas y justificaciones, sinceras o afectadas, se va configurando hasta llegar a imponerse no ya un modelo de composición poética, sino toda una reformulación de su práctica y de su puesta en circulación. Y ello afecta a todos los órdenes de la poética, la retórica y la pragmática líricas. En el plano más evidente, el de la elocutio, se aprecia la imposición del estilo gongorino, como paradigma de lo elevado y noble, aunque también mantiene vigencia el lenguaje que el cordobés reserva para lo burlesco, donde se borran las diferencias con lo más específico del ingenio conceptista, aunque sin que en el ambiente zaragozano de estos ańos haya calado con intensidad el legado quevedesco ${ }^{24}$. Mayor profundidad alcanza la que quizá es la más moderna actitud del autor

24. A este respecto, como al de otras facetas de la materia, son de utilidad los trabajos recogidos en Tras el canon. La poesía del barroco tardío, ed. Ignacio García Aguilar, Vigo, Academia del Hispanismo, 2009; en este caso, véase Manuel Ángel Candelas Colodrón, «El modelo de Quevedo", pp. 25-39. 
de las Soledades, concretada en una distancia que ya antes de sublimarse en distancia estética se manifiesta como un despegarse («que se diga y no se sienta») de los elementos de proyección biográfica o expresividad emotiva, que en los poetas posteriores se manifiesta en la completa deriva hacia lo convencional y de circunstancias; de ello dan buena cuenta unos poemarios como los repasados, con páginas trufadas de composiciones entresacadas de academias, actos públicos o dedicatorias a libros ajenos, como si en la página impresa se borraran las huellas del largo viaje que lleva desde el marcado origen de los versos a su indiscriminada recepción por lectores anónimos, en una especie de despersonalización que une tanto la escritura como la lectura. A tal efecto contribuye un tercer elemento dominante, como es el auge de lo jocoso, convertido en verdadera clave de una poética que tiene en lo lúdico (de jocus, «burla», pero también "juego») uno de sus elementos esenciales: el desasimiento de lo íntimo, a través de la vinculación a lo público, pero también el desplazamiento retórico de lo expresivo a lo estético ${ }^{25}$ se encuentran en la base de estas construcciones verbales que hoy pueden antojársenos con la apariencia de vacías, pero que se ponen al servicio de uno de los componentes fundamentales de la nueva poética, la maravilla o admiración, como muy bien señala Navarro en un "vejamen» incluido en sus Poesías varias, tras aludir con elogios a la edición de Moncayo y adelantar el nuevo volumen en preparación, para salir en defensa de una de sus composiciones jocosas:

Ese otro que se mira en su aposento, puesta la mano en el brazo de una silla, es el ilustre marqués de San Felices. Los rayos de

25. Aunque quedaría un siglo para que Kant, tras las huellas de los sensistas ingleses, sentara definitivamente las bases de lo que entendemos como estética en el sentido moderno, ya se esboza en esta poética el giro que llevaría al privilegio de la sensación, esto es, del efecto causado en el lector. En ello confluyen por igual la imposición de una incipiente estética del gusto (Sánchez Blanco, ob. cit.) impuesta por el mercado, con Lope como pontífice máximo, y, en clave retórica, el abandono de la concepción neoaristotélica de la mimesis en favor de un movere que pone el énfasis en los efectos sobre el lector. En ello confluyen, dentro de un marco general de redefinición de la lírica en busca de un espacio propio dentro del sistema clasicista, la deriva de una poética culta filtrada por el intelectualismo manierista y la repercusión de una retórica contrarreformista orientada a la predicación y sus efectos pragmáticos; véanse, respectivamente, $\mathrm{M}^{\mathrm{a}} \mathrm{J}$. Vega y C. Esteve (eds.), Idea de la lírica en el Renacimiento (entre Italia y España), Villagarcía de Arousa, Mirabel, 2004; La poètica barroca a Europa. Un nou sistema epistemològic i estètic, ed. A. L. Moll y J. Solervicens, Barcelona, Punctum \& Mimesi, 2009; y Xavier Tubau, «El De doctrina christiana de san Agustín y las retóricas sagradas españolas del siglo XVI», Criticón, 107, 2009, pp. 29-55. Iniciado décadas atrás, el proceso se intensifica y generaliza a partir de la desaparición de los grandes nombres que mantuvieron un sello personal en la lírica. 
su ingenio días ha que se vieron entrar por unas pequeñas Rimas, dando en poco volumen grandes luces de erudición (...). Anda agora poniendo como nuevo el testamento viejo, escribiendo sus historias veneradas y, como es Moncayo, las escribe con lindo aire (...). Escribiéronle a un romance que hizo a Holofernes un comento descabezado, que esta semejanza quiso guardar su autor, a quien por ser tan conocido por sus obras, palabras y pensamiento no nombro; y porque hubo algunos que la risa que notaron en los circunstantes la atribuyeron a burla, sin acordarse que la propiedad de risible, que acompaña al hombre, es hija de la admiración (pp. 146-147).

Paradójicamente, la condición de jocosa y la apariencia de vacías que exhibe y reivindica esta poesía, componentes fundamentales de su historicidad y de su trascendencia, se presentan como coherente formulación de una epistemología y una práctica social, pero también como antecedente de un principio de autonomía de lo poético como el reivindicado por las vanguardias del siglo XX.

Lejos aún de ellas, lo que sí dejan prácticamente formulado para la posteridad, y en ello resulta plenamente representativo el empeńo zaragozano de esta década, es la consagración (como soporte, cauce y, a la vez, impulso de todos los factores mencionados) del molde editorial, de la normalización del libro de poesía como proyección última del poeta en el campo literario, aun a partir de la enorme vigencia de una poesía pública con un fuerte componente de teatralización y rito social. Son muchas las composiciones que tienen su origen en estas circunstancias y que arrastran sus rasgos cuando se transfieren a la página impresa; con ellos dinamitan por completo el modelo del cancionero unitario, pero también obligan a un replanteamiento de la altobarroca apuesta por lo acumulativo de las «varias rimas». La necesidad de fijar una eficaz dispositio editorial ${ }^{26}$ se impone como uno de los elementos fundacionales en la normalización del libro de poesía, obligando a sus autores, sin esperar a la recopilación (pre)póstuma, a un severo ejercicio de organización textual, en el que no sólo se acrecienta la conciencia de su práctica y de su condición poética ${ }^{27}$; también se fijan unas marcas reconocibles para un género editorial y se instituyen unas pautas de lectura, elementos

26. De la importancia de este elemento y de los conflictos que suscita, tanto a autores como editores, da precisas referencias Begońa López Bueno, «Problemas específicos de la edición de textos poéticos: la ordenación del corpus», Mélanges de la Casa de Velázquez, XXXIII, 2, 1997, pp. 3-20; reeditado en Criticón, 83, 2001, pp. 147-174.

27. Es lo que he tratado de mostrar para los autores precedentes en La rúbrica del poeta (ed. cit.), señalando la vinculación entre la labor de edición, desde la revisión y ordenación de los poemas a la entrega al mercado, y la conciencia de autor. 
imprescindibles para la institucionalización y la conformación de un campo literario. En este punto resulta casi indiferente la alternancia de soluciones adoptadas. El seguimiento del criterio de organización métrico-formal a la manera gongorina (presente en Moncayo), la adaptación de las articulaciones de base temática siguiendo el Parnaso quevediano (como hicieran de la Torre y Sevil y López de Gurrea), la pervivencia de la miscelánea con algo de prosímetro (de Bondía a Polo de Medina) o la aceptación de la convivencia con la variedad como carácter esencial de la lírica (como muestran Alfay, Navarro y Foncalda) son sólo opciones en un común proceso de conciencia editorial y plasmación en los problemas de ordenación del corpus, que llegan a convertirse en expreso elemento de referencia en los textos prologales. Uno de éstos, debido al licenciado Ginovés y aparecido como aprobación de la edición de Díez y Foncalda resume mucho de lo señalado, incluyendo el valor de la publicación, la combinación de erudición y agudeza en la línea de la variedad y la exaltación del ingenio, pero con una clara conciencia de que algo ha cambiado desde el modelo de la generación anterior, en cuyo despliegue poético él mismo colaboró:

Y jamás me será menos costosa la obediencia [al encargo de examinar esta obra], cuando con ingenioso ardid se me libra el premio en el mismo trabajo, pues la dulzura de ellas seriamente jocosas que saca a la luz su autor, deleitan con admiración, y entre la claridad que afectan eruditísimas con las voces van intrincadas las sentencias y conceptos con mucha gala espańola, emulando más allá de toda competencia por crédito de las afluencias en los ingeniosos aragoneses las poesías que de las fecundidades castellanas perennemente fluyen cada día en tomos nuevos. Pues, si los Leonardos han sido gloria de nuestro reino en las veras, este caballero sea gloria y envidia nuestra en las jovialidades vivísimas que ha derramado en estas poesías, y, cuando los asuntos pudieran rozar al oído, la pureza con que los explica sazonan el mayor entender y la más delicada circunspección ${ }^{28}$.

$\mathrm{Ni}$ los Argensola incurrieron en la jocosidad ni dieron sus obras a la estampa. Eran nuevos tiempos, y nuevos eran los cauces poéticos que los expresaban.

En un marco de plena aceptación social, a la que corresponde con una particular atención a las prácticas públicas, la poesía encuentra un camino de normalización a través de la imprenta, que tiene en el marco de Zaragoza por estos años una privilegiada muestra de la dinámica que se extendería a

28. Mantengo la proclividad al anacoluto del original. 
partir de la segunda mitad del siglo, con las peculiaridades inherentes a su situación, si bien son estas mismas las que hacen aún más trascendente el proyecto emprendido por este grupo de autores, pues su distancia del foco madrileño implica la extensión del campo literario y su diversidad, además de introducir unos cambios fundamentales en los modelos existentes. Así, la regularización de los libros de poesía distancia a estos autores del modelo periférico tradicional, representado por los Argensola en el contexto aragonés, con una poesía marcada por el aristocratismo y el cultismo, con mucho de actualización del modelo clásico, ligado a entornos cortesanos o académicos y, precisamente por ello, limitada al cauce manuscrito. A las dos décadas de la publicación póstuma de los dos hermanos, sus herederos líricos asumen, con sus rasgos distintivos, el modelo ya más extendido en la corte, justamente donde en 1651 acaba de dar a la luz sus Obras varias Cáncer y Velasco, convertido en referente y, a todas luces, catalizador de este proceso, debido a la enorme popularidad adquirida y al prestigio ganado por un aragonés en el ya competitivo escenario madrileńo; a él alude Navarro en un pequeño parnaso («Pantaleón, Cáncer, Corral y otros ingenios de la corte»), de él incluye Alfay 6 composiciones en su antología, y muy posiblemente no sería ajena a su figura la dedicatoria de su obra por Díez y Foncalda al conde de Benavente, de quien Cáncer era criado. De manera particular, y al hilo de los acontecimientos recientes y ante la incertidumbre política, se aprecia en estos autores y en su empeño un doble objetivo de destacar una identidad local o regional, en gran medida urbana, y, a la vez, reforzar los vínculos con el trono y su administración a través de los virreyes, en cuyas academias forjan una gran parte de su producción, para darla después a las prensas como manifestación pública de esta actividad. Con el horizonte de la Paz de los Pirineos, se refuerza así el campo literario y el campo social, con un destacado papel de la lírica impresa, del libro de poesía, en un proceso de consolidación no ajeno a la dinámica política, con una abierta relación entre lo particular, el entorno urbano de Zaragoza, y lo general, con la integración en un contexto nacional, que seguía teniendo en el trono su elemento axial y en el discurso poético una de las formas privilegiadas de su visualización y fuerza de atracción.

Los poetas (y los versificadores) escriben poemas y editan libros. Sin embargo, no en todos los tiempos ha ocurrido así: el libro de poesía no ha existido siempre. Su historicidad es un hecho incuestionable, y en estos años, 
y en el caso concreto de Zaragoza, se extiende y regulariza. El protagonismo le corresponde a un grupo señero y relevante en el período, caracterizado por una semejanza de condiciones sociales y materiales, con un fuerte entramado de relaciones comunes y con unas actitudes compartidas. Tales podían ser las causas o, al menos, los requisitos para esta actitud; el efecto es un sustantivo cambio en la relación del poeta con el libro impreso, un giro que se manifiesta en la preocupación por su concepción, atención a la dispositio y cuidado por su difusión, pero también en una transformación radical en su relación con el mercado y con los lectores. Son los rasgos que van a marcar un nuevo rumbo, con más intensidad aún que las modificaciones en los elementos estilísticos, un giro en la poesía española para el siglo siguiente en su dinámica de pervivencia y renovación. 


\section{APÉNDICE I}

\section{Volúmenes de/con poesía desde 1650 à 1663 Impresos en Zaragoza}

1650, Ambrosio Bondía, Cítara de Apolo y Parnaso de Aragón, Zaragoza, Diego Dormer. [4ㅇ

1652, Juan de Moncayo y Gurrea, marqués de San Felices, Rimas, Zaragoza, Diego

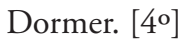

1653, Alberto Díez y Foncalda, Poesías varias, Zaragoza, Juan de Ybar. [4º]

1654, José Navarro, Poesías varias, Zaragoza, Miguel de Luna. [4º]

1654, José Alfay, Poesías varias de grandes ingenios españoles, Zaragoza, Juan de Ybar. [4을

1654, Feniso [Francisco] de la Torre [i Sevill], Entretenimiento de las musas en esta baraja nueva de versos dividida en cuatro manjares, de asuntos sacros, heroicos, líricos y burlescos, Zaragoza, Juan de Ybar. [4º]

1655, Francisco Jacinto Funes de Villalpando, marqués de Osera, Amor enamorado: fabula de Psiques y Cupido, Zaragoza, Diego Dormer. [8º]

1655, Fray Martín de la Madre de Dios, Arpa christifera, Zaragoza, Diego Dormer. $\left[4^{\circ}\right]$

1656, Juan de Moncayo, Poema trágico de Atalanta y Hipomenes, Zaragoza, Diego Dormer. [40]

1656, Miguel Colodrero de Villalobos, Divinos versos o cármenes sagrados, Zaragoza, herederos de Pedro Lanaja. [4\%]

1658, Luis Antonio, Nuevo plato de varios manjares para divertir el ocio, Zaragoza, Juan de Ybar, a costa de Tomás Cabezas. [8º]

1659, Salvador Jacinto Polo de Medina, Bureo de las musas y honesto entretenimiento para el ocio, con una novela de Montalbán, Zaragoza, Juan de Ybar (a costa de Joseph Alfay). [8]

1663, Baltasar López de Gurrea, Clases poéticas, dividense en histórica y fabulosa, amorosa, lírica, jocosa y piadosa, Zaragoza, Juan de Ybar. [4º]

\section{Otras referencias de autores aragoneses}

1651, Manuel de Salinas y Lizana, La casta Susana, paráfrasis poética de su sagrada historia, Huesca, Juan Francisco de Larumbe. [8º]

1675, Jerónimo de Cáncer y Velasco, Obras varias, Madrid, Diego Díaz de la

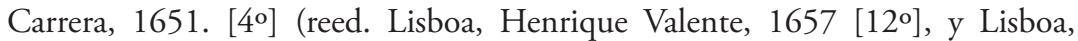
Antonio Rodrigues D'Abreu [12º] 


\title{
BULLETIN HISPANIQUE
}

\author{
ApÉNDICE 2
}

\section{Impresos poéticos en Zaragoza 1600-1649}

Se relacionan de forma abreviada y se ordenan por impresores, indicando entre paréntesis el total de títulos registrados en sus prensas (datos tomados de Esperanza Velasco de la Peńa, Impresores y libreros en Zaragoza 1600-1650, Zaragoza, Institución «Fernando el Católico» / Diputación Provincial, 1998)

\section{PEDRO CABARTE (49)}

Valdivieso, Romancero espiritual, 1613

Fray Diego Murillo, Divina, dulce y

provechosa poesía, 1616

DIEGO DORMER (44)

Luis Arellano, Avisos para la muerte, 1637

Dicastillo, Aula de Dios, 1637

Pantaleón de Ribera, Obras, 1640

Epitalamio al velo [de una monja], 1644

\section{MIGUEL FORTUÑO SÁNCHEZ}

Gabriel Lobo Laso de la Vega, Manojuelo de romances, 1601

\section{IMPRENTA DEL HOSPITAL (88)}

Argensola, Rimas, 1634 (2 ediciones) Juan de la Puente, Jardín de amadores, 1644 Honras funerales a Isabel de Borbón, 1645 Lágrimas panegíricas a Baltasar Carlos, 1646 Quevedo, Parnaso español, 1649

\section{CARLOS DE LABAYEN}

Silva de varios romances, 1604

\section{JUAN DE LARUMBE (71)}

Silva de varios romances, 1604 y 1617

Jardin de amadores (romances), 1611

Romancero del Cid, 1618

Romance a la Purísima Concepción, 1618

Lope, Romancero espiritual, 1622

Hidalgo, Romances de germania, $1624 \mathrm{y}$ 1644

Laberinto amoroso (romances), 1638

Primavera y flor de romances, 1639

Luis Arellano, Avisos para la muerte, 1640

DIEGO DE LA TORRE (26)

Justa poética a la Inmaculada, 1619

Justa poética al Pilar, 1629

\section{ÁNGELO TAVANO (47)}

Jerónimo F. de Castańa, Romances nuevos, 1604

Rey de Artieda, Discursos, epistolas y epigramas de Artemidoro, 1605

Segura, Romancero nuevo historiado, 1605

\section{ÁNGELO TAVANO (47)}

Jerónimo F. de Castańa, Romances nuevos, 1604

Rey de Artieda, Discursos, epistolas y epigramas de Artemidoro, 1605

Segura, Romancero nuevo historiado, 1605 
PEDRO DE LANAJA Y LAMARCA (47) Góngora, Delicias del Parnaso, 1640

Romances varios, 1640 y 1643

Colodrero, Golosinas del ingenio, 1642

Luis Arellano, Avisos para la muerte, 1648

JUAN DE LANAJA Y QUARTET (157)

Certamen poético, 1618

Lágrimas de Zaragoza a Felipe II de Aragón, 1621

Certamen poético a Ignacio y Javier, 1622

Villamediana, Obras, 1629 y 1634

Sandoval, La Gigantomaquia, 1630

Romancero famoso, 1635
PEDRO VERGES (64)

Primavera y flor de romances, 1636

Góngora, Todas las obras, 1643 